\title{
Press Protest and Publics: The Agency of Publics in Newspaper Campaigns
}

Jen Birks, University of Nottingham: Discourse \& Communication 4(1): 51-67

ABSTRACT: Campaign advocacy is a common but rarely researched practice in British tabloid journalism. Newspaper campaigns give an account of 'public opinion' to politicians, make explicit claims to speak for 'the public' and authentically represent them, and also address readers in an unconventional way in order to recruit their support. This article therefore examines the effect to which agency is attributed to readers and other publics in two such campaigns, and argues that publics were portrayed as active only in relation to the newspaper's activity, and as primarily as reacting emotionally to the problem. The campaigning press promote themselves commercially and politically as quasi-representatives who challenge distant and 'out of touch' political representatives with the populist impulses of 'public' demands, but without enhancing the democratic process, or publics' position within it.

KEYWORDS: Newspapers, campaigns, publics, agency, citizenship

Campaigning advocacy is a common practice in the British tabloid press, especially the local press, which is suggestive of a more European approach to political protest than is typically acknowledged. In explicitly lobbying the government to adopt or abandon certain policies or proposals, these newspapers clearly and consciously diverge from the dominant journalistic norms associated with liberal democracy, especially as associated with North America (Hallin and Mancini 2004), yet little has been written on this form of journalism (Aldridge 2003, Cross and Lockyer 2006). Similarly, whilst there has been much discussion about how active or passive the audience might be in terms of their reception of hegemonic news discourse, there has been much less about reinforcement of notions of 'common-sense' through constructions of 'public opinion' (Lewis, et al. 2005). Newspaper campaigns give an account of 'public opinion' to politicians, make explicit claims to speak for 'the public' and authentically represent them, and also address readers in an unconventional way in order to draw expressions of support. This article will therefore examine, within a Critical Discourse Analysis framework, 
the extent to which agency is grammatically attributed to readers and other publics in two such campaigns.

\section{Public opinion in news media}

The press has an important role in the democratic process by facilitating public participation. It does this most conventionally, in liberal democratic terms, by informing voters about the performance, promises and trustworthiness of their political representatives. Newspaper campaigns, in contrast, aim to directly influence politicians' policy decisions independently of the electoral process. The press claim democratic legitimacy for this on the basis that they are reflecting or representing 'public opinion'. Rather than the representation of political issues and personalities, it is the representation of 'the public' that is therefore contested. 'The public' is present in the news in a number of different ways: as sources of eyewitness or victim accounts; as contributors of argument and opinion in letters to the editor; and as the subjects of stories.

As sources of eyewitness and victim accounts, members of the public are afforded a measure of publicity to contribute a different perspective from the dominant official accounts (Fowler 1991: 16); however, this agenda-setting role fits within the liberal model, unlike campaign advocacy. Letters to the editor can allow members of the public to contribute to political debate, but findings from the US suggest that letter editors "prefer the emotionally-charged stories of individuals" over overtly political views, which were regarded as a "manipulative discourse" (2001: 311), lacking "sincerity, authenticity and truth" (2001: 313), suggesting a view of politics as intrinsically self-interested and corrupt.

The key aspect of campaign journalism, however, is stories about 'the public', or stories in which 'the public' is attributed some particular opinion, preference or feeling. These stories occasionally draw on opinion polls or make reference to 'vox pops' interviews, and very occasionally draw on political protest as an indication of 'public opinion', but are most often based on the unsupported inference of the journalist (Lewis, et al. 2005). This demonstrates, 
as Lewis et al put it, "that journalists feel an obligation - and an ability - to either speak for or about the public" (2005: 27). This is of particular concern if journalists make such claims from a position of ignorance.

Lewis et al found that substance of news representations of public opinion in the UK and US was restricted to reactive approval or disapproval, more often of politicians rather than policy (2005: 67-9). Publics were portrayed as "passive observers" who were only attributed "fears, impressions and desires" (2005: 48-9) not opinions, and were discursively excluded from political participation. The authors suggest that this could be because the political news is "usually about what politicians do, and not necessarily what people want them to do" beyond broad agenda-setting priorities (2005: 50). In that case, campaigns - which are specifically about what people want politicians to do - should portray publics in more active terms.

\section{Public agency and democracy}

The press has a significant role as the "principal mechanism" of communication between and among elites and publics, and in particular serves a "correlation" function among publics and a "surveillance" function for politicians (Price 1992: 80). Indeed, US research by Susan Herbst found that legislative staffers (civil servants and policy advisors) "believe that media and public opinion are synonymous" (Herbst 1998: 187). This is significant because public approval is valuable political capital to politicians, and is actively sought, rhetorically claimed, flattered and placated, as well as purposefully "shaped and directed". Anticipated electoral behaviour can be even more significant than actual votes: "the political power of an attentive public lies, then, 'not so much in what it does, but in political actors' perceptions of what it might do"' (Price 1992: 80).

Vincent Price distinguishes various specific publics as defined by participative behaviours (1992: 36-43). The voting public (estimated at $70 \%$ participating at least occasionally) are sufficiently active to participate electorally, but are not necessarily more informed than nonvoters; the attentive public are the actual audience for political communication - though this 
may not be identical to the imagined audience being addressed - and tend to be more knowledgeable on public affairs generally (estimated at about a third of the population), whilst only a fraction (15\%) are thought to be a truly 'active public', including 'interest elites'. All of the above categories of attention and activity can be thought of as fluid across different issues, and may be constituted differently as distinct 'issue publics', potentially in line with specific interests or as those directly affected by an issue.

Active issue publics would include those invited to participate in policy networks via consultation mechanisms, and the attentive issue publics would be those addressed by campaigning activity to recruit their support.

A campaign may conceive of its target audience as the generally attentive public (as perhaps most campaigns do) or attempt a more issue-specific approach by appealing to those people who are particularly attentive to a given problem. (Price 1992: 43)

The attentive public are invited to respond by "thinking about what they read and see as well as in forming and expressing (sometimes) opinions on the question", but those opinions may still be only limited to approval or disapproval of the proposals developed by active publics, or even solely by political leaders. It is these aspects of participative behaviour that this study examines.

\section{Method and sample}

The texts examined in this analysis form part of a larger sample of articles associated with campaigns with political objectives undertaken by Scottish newspapers between 2000 and 2005, which also included interviews with the relevant editors and journalists. Whilst a broad thematic content analysis of the case study campaign narratives has been carried out elsewhere, here a more close analysis will be made only of those paragraphs in which explicit reference to various generalised publics is made. Of the six campaigns that made up the full sample, the two that made the strongest reference to publics have been selected for in-depth analysis here, comprising 343 articles. From these, 423 paragraphs were identified, through 
use of the search function of NVivo qualitative data analysis software, as being explicitly about publics.

Koenig (2004) recommends NVivo for frame analysis, but because data can be retrieved in context it is also useful to facilitate discourse analysis. Searches, returned as 'nodes', functioned at two levels in the process, firstly to collate sections of the texts that were of interest for further analysis (as a resource), and later to check the representativeness or significance of frames and discourses identified in that in-depth analysis (as a reference). The relevant resource search terms in this instance were "readers"; "the public"; "public opinion" (and other nominalisations such as "public support" or "public opposition"); reference to the nation such as "Scots" and "the people of Scotland", and "communities". Uses of the second person pronoun "you" were also hand-coded to select only those used by journalists to address readers directly. Additional reference searches included lexical choices such as "tough" or "arrogance", and noun or verb phrases in particular syntax patterns, such as "[take(s)/took] drugs" or "[...] by drugs". All direct quotations of and attributions to sources in the sample texts were also systematically hand-coded by type of source, and the type of article (such as news, feature, or letters page) were coded as 'attributes' of the documents.

Fairclough (2001) sees discourse as social practice, a product of interaction, struggle and conflict in its production and the site of the enactment of social relations. To an extent, this practice is evident in the intertextuality of news texts, whereby common beliefs and interpretations among participants, including the imagined audience, are presupposed; and in the conversationalization of news discourse, whereby the voices of ordinary people are “ventriloquized" by journalists (Fairclough 1995, 1998). This quasi-presence of 'the/a public' in political news discourse is, as Fairclough points out, subject to misrepresentation (conscious or otherwise) and is not necessarily a democratizing force. Hegemonically, such notions of 'common-sense' can serve to reproduce existing power relations by encouraging people to see dominant values as their own, but the power of the newspaper in claiming to represent and speak for publics is furthermore perpetuated by reproducing a 'common-sense' notion of citizens as powerless and passive. 
The key analytical tool in this case is therefore the agency attributed to publics. Though often motivated stylistically (as in academic style, see Billig 2008), journalists' use of the passive voice ('passivization') and of nominals in place of verbs ('nominalization') are noted as forms through which journalists exclude participants and conceal processes, and therefore remove agency. The representation of publics is compared with the presentation of the newspaper as an agent interacting with or acting on those publics. These textual properties are further contextualised in relation to the production of the specific articles, with reference to interviews carried out with journalists who worked on the campaigns. This reveals the ways in which journalists understand and legitimate their representation of and interaction with readers and other publics.

\section{The newspapers and campaigns}

The Daily Record is a Scottish tabloid based in Glasgow, which supports the Scottish Labour Party and espouses a mixture of left-leaning and populist politics. Its campaign 'against drugs' began as a public appeal for information about heroin dealers in a populist 'name and shame' campaign, but became more overtly political when a protest march was announced calling for government action to deal with this form of crime and deviancy. The stated aims were to call for tougher legislation and enforcement of existing law against drug dealers, but more commonly and more vaguely to "rid [the/Scotland's] streets of [drugs/drug dealers/pushers]" (seven times).

The Evening Times is a local city evening newspaper for the Greater Glasgow conurbation. Its campaign against the proposed closure of one of the city's maternity hospitals was explicitly oppositional and overtly critical of the local Health Board. A petition was circulated as an articulation of public opposition to the policy and delivered by the editor to the Health Minister and the Scottish Parliament's Petitions Committee. The aim was initially to 'save' the Queen Mother's Maternity Hospital (and the connected but unthreatened Yorkhill Hospital for Sick Children) from closure or relocation, then - when this emerged as a compromise solution that could be claimed as a victory - simply to retain the link between maternity and neo-natal 
care (though eventually it was agreed that this site would not be Yorkhill), but without acknowledging this as a shift in position.

\section{Representation of publics' agency}

Both newspapers made significant reference to their "readers" as a specific attentive public, though this was more common in the Daily Record. Conversely, references to "the public" as a singular, definitive entity were more common in the Evening Times, partly because it was used by supportive political and clinical sources (25 and 14 times respectively, of a total 49 quotes). The term was also frequently used by the Daily Record's police sources (14 of 20 quotes) in the context of "members of the public", reflecting the way they encountered citizens - as victims and witnesses. Other terms commonly used in place of "the public" in the Daily Record, and employed in similar ways, included "communities", "Scots" and "the people of" Scotland, Glasgow and so on, occasionally to mean a group of citizens with common interests and values, and an 'issue public' in as far as they were commonly affected by and concerned about the issue, but often to mean an aggregate of individuals, or a location or environment.

\begin{tabular}{|l|l|l|}
\hline & Daily Record & Evening Times \\
\hline "Readers" & $34(20 \%)$ & $23(10 \%)$ \\
\hline "The public" & $30(17 \%)$ & $82(25 \%)$ \\
\hline "Public opinion" & $1(1 \%)$ & $20(8 \%)$ \\
\hline "Scots" & $15(10 \%)$ & $6(3 \%)$ \\
\hline "The people of..." & $11(9 \%)$ & $31(11 \%)$ \\
\hline "Communities" & $144(56 \%)$ & $26(10 \%)$ \\
\hline
\end{tabular}

Table 1: Number of paragraphs containing search terms (percentage of articles containing search terms in parentheses)

References to readers as a specific public will be addressed first, followed by the various formulations of a more general public. 


\section{Readers: a supporting role}

In the Evening Times "readers" were framed semantically as 'agents' in 11 of 23 references, eight of which were framed in active syntax. In the Daily Record's drugs campaign "readers" were agents in more than half of sentences referring to them, though seven of those were in the passive voice (for example, "named by Record readers").

\begin{tabular}{|l|c|c|c|c|}
\hline & \multicolumn{2}{|c|}{ Daily Record } & \multicolumn{2}{c|}{ Evening Times } \\
\hline & Count & Col \% & Count & Col \% \\
\hline "Readers" & $\mathbf{3 4}$ & $\mathbf{1 0 0 \%}$ & $\mathbf{2 3}$ & $\mathbf{1 0 0 \%}$ \\
\hline Agents & 19 & $56 \%$ & 11 & $48 \%$ \\
\hline active & 12 & $35 \%$ & 8 & $35 \%$ \\
\hline passive & 7 & $21 \%$ & 3 & $13 \%$ \\
\hline negative / conditional & 0 & - & 0 & - \\
\hline Nominalised & 1 & $3 \%$ & 5 & $22 \%$ \\
\hline Affected participant & 14 & $41 \%$ & 7 & $30 \%$ \\
\hline
\end{tabular}

Table 2: Syntactic attribution of agency to readers

The Evening Times made six references specifically to readers signing or having signed the petition", but the other verbs attributed to them - that they "show[ed] their anger" (ET 17/10/03), "protested" (ET 30/10/03) and "condemn[ed] the threatened closure" (ET 21/10/03) - are all expressive actions that were an interpretation of the same event of signing the petition. The following examples were the first two to occur; later instances became increasingly formulaic updates in the construction " $<$ number> Evening Times readers have [already] signed [a/our/the] petition".

Readers are also signing up to get their message across to Greater Glasgow NHS Board, which will decide the fate of the two hospitals on October 21. (ET 11/10/03)

13,000 sign our petition. Evening Times readers show their anger over Yorkhill proposals. (Headline, ET 17/10/03)

Both of these excerpts assert the argument that readers oppose the hospital closure. In the first, this assertion contains two propositions pertaining to the readers, the main proposition that they are signing the petition, and the embedded relative clause that they aim to get their message across. This ascribes motivation and therefore a conditional relationship - readers 
sign the petition as a consequence of having a message for the Health Board, and that message is therefore independent of and prior to the petition and perhaps, by extension, the newspaper's campaign as a whole. The newspaper therefore claims to take a facilitating role rather than a persuasive role in relation to this expressive agency, however, the only concrete actions are oriented to the Evening Times - as emphasised by the appearance of the name of the newspaper in half of those instances - suggesting that citizens only have a voice through press mediation.

The second excerpt, which asserts a similar expressive intention by implying a connective through "local coherence" (Van Dijk 1988), is more explicit about the substance of the message, identifying it as an expression of emotion. Across the whole campaign anger was the dominant emotion, and most frequently (16 times) appeared in this nominalised form (from '<subject> [is/are] angry') - in addition to readers' "anger" was attached to "protesters", the "public", "Glasgwegians" and others, and the subject was omitted in seven cases, such as "there is a real anger" (MSP ${ }^{\mathrm{iii}}$ quoted in ET 20/11/03). These interpretations of the action of signing a petition are consistent with the topic of 'protest', and rhetorically locate the event in a frame expected to be familiar to the audience and in terms of emotional resonance in order to make it memorable (Van Dijk 1988). In doing so, however, the newspaper implies that protest is predominantly motivated by emotion rather than reason.

In the Daily Record, the actions attributed to readers were again in support of the newspaper's actions, but even more explicitly so, being exclusively oriented toward the newspaper and not the authorities. Attributions of reader agency largely occurred early in the campaign, during the name-and shame stage, and related to reporting drug dealers to the newspaper - readers "shopped", "named", or "identified" dealers six times, and "called", "phoned" or "rang" the newspaper seven times, whilst in relation to the protest march they were largely affected participants. In addition, the regular occurrence of the newspaper title in these instances not only indicates a claim to ownership of the readers ("[Daily] Record readers" eight times; "our readers" five times) but also places the newspaper in the position of agent. 
As the Record exposed the dealers, the police war against drugs gathered strength, backed by our readers. (DR 02/12/00)

Once the kids are hooked, the dealers have a steady stream of future customers. But thanks to Record readers, the fightback is on. We are naming, shaming and investigating dealers identified by our readers - and the response has been overwhelming. (DR 11/12/00)

The first connects three discrete propositions, and by doing so, suggests a causal relationship between the strengthening of the police's (nominalised) war against drugs and the actions of the two agents - the Daily Record (actively) exposing the dealers, and their readers (passively) backing them. The final sentence of the second example is similarly constructed - emphasis is placed on the actions of the Daily Record "naming, shaming and investigating dealers", and whilst readers are also (passive) agents, identifying those dealers, the relationship is one of specification (which particular dealers). In both, though readers are clearly credited, the newspaper's action is foregrounded.

Furthermore, readers' actions in calling the newspaper were presented as evidence of their dependence on it to speak up for them.

Concerned Daily Record readers called us as part of our name and shame campaign, begging us to highlight Holmes' shady dealings. (DR 06/12/00)

Both verbs are transitive with the Daily Record as the object of the action - the journalists were called and begged - and yet the semantic association of 'begging' is that the beggar is in the subordinate position. The readers are also described by the adjective "concerned", and therefore in an emotional state. Daily Record readers were also described as "anxious" (DR 01/12/00), "desperate" (DR 10/03/01) and "sickened" (DR 11/01/01), suggestive of vulnerability to or dependency on the actions of others. In contrast, the Daily Record portrayed itself and its campaign as "hard-hitting" (10 times) and part of a "war [on/against] [drugs/dealers]" (60 times), and as instigating a "tough" response (11 times), lexical choices that indicate the newspaper's positioning of itself as a protector in terms of legitimate aggression against the perpetrators, using the common metaphor of state-sanctioned violence ('war on drugs'), rather than as a champion or enabler. 
In the instances where the newspapers' readers were syntactically 'affected participants', their cooperative and supportive role was more explicit. Most commonly the agent affecting readers was the newspaper. In particular, the Evening Times "urged" its readers to sign the petition, and the Daily Record "asked" or "urged" its readers to join the protest march.

We ask again that you, our readers, join us and march together on April 1 to tell the dealers their time is up. (Leader, DR 27/02/01)

Now the Record is urging readers to go one step further and march alongside families whose lives have been blighted by drugs. (DR 10/03/01)

The first asks readers to march with the newspaper, whilst the second asks them to march with the victims (who are also affected, but by "drugs"), but the most significant characteristic of both these examples is that they are both speech acts - their expression performs the act of a request. Furthermore, whilst the second excerpt refers to readers in the third person, in keeping with stylistic notions of journalistic distance, the first breaks with this convention to speak in the first person plural addressing readers directly in the second person, with the third person descriptor in a sub-clause as a specification ('our readers') and then with a possessive pronoun. Newspapers do not usually directly address their readers, either in the second person "you", or through "reader-addressed speech acts" other than assertions (Van Dijk 1988: 74), especially not in news articles.

It is also rare for newspapers to use the imperative, since readers are perceived to be resistant to being told directly what to think. Even in the campaigns it was usually reserved for the early stages, and was often replaced by reports of the level of support so far. The Evening Times used the imperative three times to tell readers to "save these hospitals" and to "add your name" to the petition a further three times. In relation to invitations to "shop a dealer", the Daily Record used the imperative to tell readers to "phone us" (DR 24/02/01) and "tell us" (DR 03/05/01). However, of 62 uses of "join" in the context of the protest march, only one was truly imperative "Join the fight!" (leader column, DR 20/02/01) and of 223 references to the march only one imperative "march with us".

But the point of this campaign is that we are not powerless. There is no need for us to feel unable to do anything to stop the evil of drugs ravaging our communities. All of us 
can stand up and be counted. All of us can make a difference. March with us on April 1 . Together we can win. (Leader, DR 27/02/01)

This paragraph is highly rhetorical and the style is more precisely redolent of political campaigning rhetoric. Even for tabloid journalism, the sentences are very short, and contain unsubstantiated assertions (appealing to the myth of perfect agency) and formal repetition of "all of us can" - evocative of the recent campaign rhetoric of Barack Obama ("yes we can").

The conditional was used in two distinct but overlapping ways - as part of an enabling discourse of possibility, and to modulate the imperative. The Record used "you can" three times, such as "you can help us get the dealers off our streets" (DR 27/02/01), and the Evening Times as many as 15 times, including "You can save the Queen Mum's" (ET 22/10/03). Readers' agreement was occasionally framed as conditional rather than assumed, such as "If you want to save these hospitals" (ET 10/10/03), but the implied binary opposite is not to want to save them, suggesting negligence rather than a preference for the Southern General or support for the case for centralisation. The purpose of this was partly to make claims for the effectiveness of action and consequently to motivate readers to act, but also to frame the newspaper's opinion as the dominant consensus.

The Evening Times also instructed readers to "tell them what you think" (six times), "tell us what you think" (four times), as well as "tell us about your experiences" (ET 17/10/03). However, the newspaper was careful not to tell the readers what to think, but to tell them to report what they (already) think to the paper or (more democratically) to political leaders.

Write to them, or any MPs or MSPs you know, telling them why you think Yorkhill's highly-successful sister hospital set-up should be preserved and stay where it is at present. Ignore the bureaucrats and bean counters who claim paediatric care is best delivered within a vast general hospital set-up - or that Yorkhill cannot continue to function in splendid isolation. (Leader, ET 09/10/03)

In practice the newspaper was only looking for a particular type of response, one of support, but framed that opinion as a foregone conclusion - "telling them why you think...", which appears to invite reasoned argument and the expression of personal opinion, but is a modulated form of the alternative "tell them that you think...", providing the preferred opinion 
and explicitly closing down alternative arguments by instructing readers to "ignore" them, rather than setting out reasons for disagreement.

The Daily Record also used the 'inclusive we' to construct consensus (Fairclough 2001: 16874, Fowler 1991: 49-50); this occurred 83 times in 45 articles, contributed most frequently by sources (51 times) and more particularly by politicians (24 times). In particular, paralleling the above direct address, the campaign repeatedly declared "we can" (29 times, eight from politicians, three from affected individuals) and "we need to" (three times, two in quotes from politicians, one celebrity), and specifically, "we can win" (eight times, two in quotes from politicians), as well as "[together/united] we'll beat..." (five times) largely without specifying measures that should be taken to achieve this, beyond the march itself. The Evening Times used the 'inclusive we' less - only eight times - perhaps because their objective was more specific and policy-based rather than expressive.

Whilst it has already been shown how these rhetorical techniques are consistent with political campaigning, they can also be interpreted as promoting the campaigns to readers with commercial sales techniques; indeed the line between political campaigning and marketing has blurred in recent years and decades. Fairclough (2001: 168-174) identified all of the above discourse elements as common features of advertising as an order of discourse, including "synthetic personalisation of audience members" through the direct form of address in the second person, address in the imperative ('have a break, have a kitkat'), and the inclusive 'we' (see also Fowler 1991: 49-50). Much of the "ideological work" of advertising discourses, according to Fairclough, is through such a construction of the consumer, in this case as part of the newspaper's (constructed) consensus and of a 'public' whose interests are being pursued or defended by the newspaper. This was confirmed in interviews, where editors and journalists at the newspapers discussed campaign journalism in terms of branding and selling the newspaper as a community champion. Whilst newspaper readers clearly are, in some sense, consumers whose purchase of the newspaper may be (misleadingly) conflated in some cases with their assumed approval of the newspaper's stated opinions, 
references to more general publics might be expected to be represented as more independent of the newspaper's activity.

\section{The public: feeling and believing}

In contrast to "readers", "the public" were less frequently portrayed as agents, but were more frequently attributed opinions as well as feelings. In The Evening Times, agency was attributed in little more than a quarter of references to "the public", and in just under half of these their action was de-emphasised or denied (as passive, conditional or negative). Similarly, in the Daily Record "the public" were less frequently attributed agency than readers, and those actions were often conditional, especially where the references originated from police sources.

\begin{tabular}{|l|c|c|c|c|}
\hline & \multicolumn{2}{|c|}{ Daily Record } & \multicolumn{2}{c|}{ Evening Times } \\
\hline & Count & Col \% & Count & Col \% \\
\hline "The public" & $\mathbf{2 9}$ & $\mathbf{1 0 0 \%}$ & $\mathbf{8 2}$ & $\mathbf{1 0 0 \%}$ \\
\hline Agents & 7 & $24 \%$ & 21 & $26 \%$ \\
\hline active & 3 & $10 \%$ & 11 & $13 \%$ \\
\hline passive & 0 & - & 3 & $4 \%$ \\
\hline negative / conditional & 4 & $14 \%$ & 7 & $9 \%$ \\
\hline Nominalised / state & 14 & $48 \%$ & 15 & $18 \%$ \\
\hline Affected participant & 8 & $28 \%$ & 46 & $56 \%$ \\
\hline
\end{tabular}

Table 3: Syntactic attribution of agency to 'the public'

To some extent, the Evening Times portrayed "the public" in a similar way to "readers" in as far as their "feelings" and "support" were extrapolated from petition signatures.

Newsagents have inundated the Evening Times with requests for more petition forms as the public makes its feelings clear. (ET 21/10/03)

The Evening Times will present the petition to Scottish Health Minister Malcolm Chisholm to show how strongly the public supports the hospitals. (ET 21/10/03)

Again, the title of the newspaper is present, though ownership or leadership of the public is implied rather than explicitly claimed, and as with readers the substance of their nominalised "feelings" is unclear. However, some claims of public support were more specific. 
The Evening Times will present a petition to Scottish Health Minister Malcolm Chisholm to show how strongly the public supports the unique relationship of the hospitals, which allows poorly new-born babies to be treated on site as soon as they are born. (Feature, ET 10/10/03)

This similarly describes the Evening Times' (future) action, to present the petition to Chisholm (with specification of his role); and their intention (cause and potential consequence), to show Chisholm; the content of the message, that the public support the relationship of the hospitals. However, this already more specific object of their support is further specified as "unique" and by purpose. As a consequence, this actually attributes a reasoned opinion to "the public", though again only as expressed via the petition.

Far more commonly, however, the beliefs of the public were not described in terms of their opinions about what should be done, but their "trust" or "faith" in those who decide what will be done. This was particularly commonly used by politicians.

"The public has lost trust in these processes and become very cynical and, I think, would want to see them handed over to an independent body." (Paul Martin MSP (Lab) quoted in ET 17/01/04)

A GLASGOW patients' group has warned the city's health board the public has no faith in its plan to shut the Queen Mother's maternity hospital. [...] The criticism echoes a warning from Glasgow City Council that the public no longer trusted the board. [...] Its submission said: "The public cannot have confidence around the strategic proposals to close the Queen Mother's Hospital and transfer fetal medicine when fundamental issues require to be addressed." (ET 02/03/04)

Three verbs are associated with the public in the first quote; the public's action of losing trust is an involuntary action, becoming cynical is entering into a state more than a conscious action, and the final preference is conditional - 'would want to see' suggests a phrase of qualification such as, perhaps, 'if we asked them'. Further, Martin's assertion is that the lack of trust in one body can be addressed by replacing it with another. The second excerpt begins in much the same way, where trust is the main objective in itself, and "faith" is suggestive of a blind trust inspired by personal qualities, however, this is only true of the Evening Times' summary, whilst the final direct quotation reveals that the council actually argued that the public were unable to come to a judgement on account of incomplete 
information or debate. Whilst confidence can mean trust, reliance or faith it can also mean certitude or assured expectation, and this meaning is suggested by the specification that "fundamental issues require to be addressed" before the public can be certain that the proposals are sound.

The Daily Record also attributed feelings to publics, principally led by politicians anxious to demonstrate that they too - like the newspaper - understood how people felt, and also to direct negative emotion away from themselves and their policies.

"The tremendous turn-out proved just how much feeling the people of Scotland have against drugs" (MSP in letter to the editor, DR 11/04/01)

THE First Minister said: "The Daily Record's campaign has embodied the feelings of the Scottish people". (DR 30/03/01)

The verbs attached to the campaign here reflect an assumption on the part of the politicians as much as the journalists that the newspaper had expressed an authentic public opinion that preceded the campaign - it "proved" what was already known, and "embodied", somehow corporeally represented, a vague, amorphous 'public feeling'.

This feeling 'against drugs' suggests a normative disapproval of drug use in keeping with a conservative 'moral panic', which places blame on deviant individuals rather than on structural problems with political solutions, and is associated with the status quo rather than progressive change. However, the reference to "drugs" rather than 'drug use' as the object of disapproval specifically avoids othering drug users. Throughout the campaign, users were instead framed as affected by drugs; there were 24 instances of the construction "[victim/community] [verb in past tense] by drugs", including having been "blighted" (three times), "ravaged" (twice), and "killed" (twice) by drugs, with "drugs" as the agent in the sentence, and users as affected participants. In comparison, there were 11 instances of active syntax with the drug users as the subjects ("take/use drugs" or other conjugations and tenses), eight of which were quotes from affected individuals, and five of them were either negative (denials) or in the conditional tense. However, this discourse of vulnerability and victimisation was not coupled with a structural explanation for drug use and therefore with a 
political solution, but shifted blame to drug dealers and hence still privileged a law and order solution.

Therefore the political interpretation was that the campaign was aimed at encouraging public cooperation with the authorities against drug dealers, an assessment shared by the police. Police sources interpreted people's cooperation with the newspaper's campaign as support for the police, and as a form of (mediated) cooperation with their investigations.

"We welcome the Record's campaign because anything which involves members of the public passing on information or intelligence about drug dealers is very positive. (Police source quoted in DR 02/12/00)

"That detection is helped a great deal if the public let us know what is going on. We rely on that kind of help." (Police source quoted in DR 19/12/00)

The public role here is active, though conditionally so in the second example, transmissive or communicative ("passing on", "let us know") and assistive (implied as agent in the intransitive "is helped" with the nominalisation "detection" as the subject-patient, and in the nominalised "help"), but individual ("members of the public" - meaning civilians, non-police) rather than a collective, social or democratic participation.

The claimed consequence of the campaign is that drug dealing activity is reported, the implication being that the cause of the problem was a failure of enforcement, perpetuated by public frustration and therefore unwillingness to cooperate. In particular, the newspaper reported local people's frustration that operations "came to nothing" (DR 03/02/01), and that dealers were thought to consider themselves "untouchable" (three times). As in the Evening Times campaign, this could be related to trust in the body charged with dealing with the problem, but in this instance, the solution is not even to change the institution, but to persuasively restore public trust. In response to the campaign, the police were described as "confident that the tide is turning in the war against drugs, and that more and more people are on their side" (DR 06/12/00), suggesting that the public had a choice between taking the side of the police or the side of the drug dealers. 
The same rhetoric was applied to a politician, then SSP leader Tommy Sheridan, who opposed enforcement solutions: "whose side is he on?" (DR 03/03/01). Sheridan was judged not only to be "out of touch", but "heartless and egoistic", "disrespectful, mean-spirited, selfserving and arrogant", "insensitive", "uncaring", and giving "a two-fingered insult to the victims of drugs and their families" (leader column, DR 03/03/01). Similarly, Sheridan's later proposal for free prescription heroin (to minimise the health and crime consequences of the black market) was reported to have been "roundly condemned", and "attacked" by "families of dead addicts" (DR 10/03/01). These criticisms suggest that the political objectives (largely tougher enforcement) could not be challenged because they could not be separated from the personal feelings experienced by those affected, and also an uncritical 'common sense'.

"The case for the campaign against hard drugs is irrefutable. It is so obvious it does not even have to be stated" (leader column, DR 03/03/01).

Since the opposite of being "against hard drugs" is to be 'for them', this assumes that the legalisation of heroin equals a tolerance of the harm caused, rather than a reduction in harm. The common sense understanding of crime and deviance is as the imposition of social norms - disapproval of heroin - not the objective source of harm. The effect of the focus on emotions such as fear, disapproval and frustration is that the solutions that emerge address those feelings rather than the problem.

The most typical representation of "the public" was as affected participants, but unlike "readers" they were affected by the actions of politicians and public officials. This was particularly true of the Evening Times, where the public were frequently described as 'beneficiaries' having been addressed, and specifically having had information (or "misinformation") "compiled", "distributed", "provided" or "made available" to them (nine times). To some extent, this reflects a concern that citizens were enabled to make an informed contribution to the debate, though the focus was on how the public were "misled" and "misinform[ed]" (eight times) and therefore more on the wrongdoing of public officials in a traditional 'watchdog' mode. 
The public were furthermore described as being "ignored" and "dismissed" by the health board, and were not "listened to" or "encouraged" to participate in the consultation. Politicians were the source of half of these assertions, especially local and opposition politicians such as Sandra White, an SNP Glasgow list MSP ${ }^{i v}$.

"Instead they ignored clinicians and the public, as they have continued to do so since, and just railroaded their idea through." (Sandra White MSP (SNP) quoted in ET $19 / 04 / 04)$

This demonstrates how listening was defined as acting on public preference. Previous decisions where critics' arguments were not accepted were presented as evidence of the Health Board having been inflexibly single-minded about their proposal ("railroaded"), an argument echoed by other sources such as a health professional who argued that "It has not listened and it is not going to listen to what people want this time." (health professional quoted in ET 24/10/03). Correspondingly, the Health Minister was warned that he must demonstrate evidence of listening.

STEP 2 Write to Health Minister Malcolm Chisholm. He has said he will listen to the public on this issue. We must challenge him to honour his pledge. (ET 13/11/03)

Given that the public were portrayed as simply supporting the hospitals and opposing the closure, it is hard to see how this statement of preference could be "honoured" in any way other than capitulation.

This is particularly clear where the public's expressive actions of thinking, believing or wanting were nominalised as "public opinion", "public support", "public opposition" and so on. Not only does this background publics' agency but it obscures or simplifies the substance of their opinions into a binary of want / don't want. Without reasoning, it is expressed as a battle of wills.

HEALTH bosses in Glasgow have come under fire after insisting no amount of public opinion will force them to change their minds over the closure of the Queen Mum's. (ET 27/10/03)

And public opinion, as expressed by the 156,000 signatures gathered by the Evening Times, was treated with contempt. (ET 26/04/04) 
These excerpts both relate to the statement by Catriona Renfrew of the Health Board that the consultation was not a referendum and that it was "not a matter of how many million signatures" the newspaper gathered, but of reasoned argument (ET 27/10/03). The newspaper instead portrayed "public opinion" only as a quantitatively defined force of pressure ("amount, 156,000 signatures") that could not be challenged or refuted, and to attempt to do so was interpreted as showing "contempt" for 'the public'. Disagreement with opinions attributed to 'the public' was also interpreted as "an insult" (four times), and the Health Board were described as having "poured scorn on the public outcry" (ET 20/02/04). Their focus on clinical argument over instinctive preference was interpreted as patronising "arrogance" and being "high-handed" (Sandra White (SNP) quoted in ET 20/11/03), further suggestive of a populist approach to social and political issues.

Both the Evening Times and the Health Board separated active issue publics who could contribute reasoned clinical arguments from the broader attentive publics who were concerned about and potentially affected by the decision. However, the approach to attentive publics differed. The Health Board ran consultation exercises with patient groups on the specifics of the proposals, which were ignored by the newspaper, whilst the newspaper took a more quantitative approach, which was dismissed by the Health Board. Whilst the petition was potentially more representative, it was representative only of an assumed instinctive, emotional response. This assumption on the part of the journalists was, at least in part, a projection of their own instinctive responses.

And I think in the early days the feeling was 'this is a bad thing', and that the public see it as a bad thing, and we tend to agree with them on that. Without being entirely sure.... It's a bad thing, it just is, it'll be unpopular, it just... doesn't seem right. (John McCann, Health Reporter, Evening Times)

Whilst the Evening Times did, elsewhere, offer reasoned arguments for its stance against closure, these were intended for a political, not a general audience, as part of a two-pronged approach to placing pressure on the Health Minister and his colleagues; that "people make them want to, and then the clinical side of it gives them an excuse to do it, or the will to do it, whether politically or personally" (McCann). Nonetheless, this was still more reasoned than the Daily Record, which relied even more on common sense assumptions about public 
opposition to legalisation, and a more personal vilification of political opponents as callously insulting the feelings of 'the public'.

\section{Conclusion}

Campaign journalism, in common with other forms of news on social and political issues, makes frequent reference to publics. Their claims to represent 'public opinion' lend the newspapers the impression of influential force and democratic legitimacy, without necessarily providing a meaningful voice for citizens. More unusually, frequent reference was made to forms of protest as evidence to support these claims, but only where those protests were initiated by the newspapers. Readers were therefore portrayed as agents only in as far as they supported the newspaper through expressive action delineated by the newspaper. Given that the action was reactive, this is consistent with Price's 'attentive public' rather than a truly 'active public', despite the activist associations of the protest tactics. If readers were expected to be attentive to arguments presented by the newspaper-as-activist this would be partly consistent with Habermas' (1994) notion of deliberative democracy, but instead of forming an opinion from discussion in the public sphere, publics were portrayed as having a prior instinctive opinion or as reacting emotionally to the problem.

Readers' role in the protest was therefore to respond emotionally and instinctively to the problem, to recognise the newspaper as the representative that was 'in touch' with their feelings, and to lend them support in the form of quantitative force of pressure. As Berezin (2002) argues, the appeal to emotional empathy can help to consolidate fellow-feeling and thus support for collective responsibility beyond self-interest, but it can also be rhetorically useful in the construction of consensus. It is possible that emotional responses are regarded as being more authentic, valid or altruistic toward those suffering the effects of the problems identified, but more clearly it is intended to demonstrate that (assumed) dominant beliefs that drug use is solved by prohibition and hospital closures are 'bad things' - are incontrovertible. 
Discourses of enabling and urging were aimed at emotional responses precisely because they could be argued to be prior beliefs, so avoiding an overtly political argument that is expected to be regarded as manipulative or boring and therefore rejected. The use of protest as an expressive form of consolidating group identity and belief is not, however, peculiar to a conservative or mainstream opinion, but is also important in alternative or marginal group protests, which may not be primarily aimed at changing onlookers' minds (McLeod and Hertog 1992).

There is a radical impulse behind newspaper campaigning and a not entirely cynical intention to represent or give voice to an affected and/or attentive public, but newspapers approach this in largely the same way as they characterise politicians' treatment of 'the public', deciding the interests and preferences of 'the public' on their behalf, avoiding any kind of controversy or disagreement, and being reluctant to change their mind in the face of new evidence or arguments. The participatory and deliberative potential behind the enabling discourse is not fulfilled, since newspapers attempt to win largely through brute force of populist support, and appeal to the imagined self-interestedness of politicians (to avoid falling foul of 'the court of public opinion').

Publics are portrayed as active agents in relation to the newspaper (other than when addressed by it), but as affected by politicians and officials, especially as misinformed by them. Coupled with the discourse of trust this suggests that newspapers are keen to portray themselves as the trustworthy political representative of their readers in place of elected politicians, but on the same terms, expecting the readers to entrust their democratic sovereignty and legitimacy to the newspaper's decision-making. For this reason, a truly enabled and empowered public would threaten the continued relevance and political influence of the press. The campaigning press promote themselves commercially and politically as quasi-representatives who challenge distant and 'out of touch' politicians and officials and communicate the populist impulses of 'public' demands, but without enhancing the democratic process, or publics' position within it. 


\section{NOTES}

i However, studies of the representation of protest groups and movements in the US have suggested that the mainstream press portray their political opinions and actions as deviant from the social norms of 'the public' more generally (McLeod and Hertog 1992).

ii In all the petition was referred to 224 times, 23 of which were in relation to "the public", and nine in relation to "readers". The running total of signatures was reported 73 times.

iii Member of the Scottish Parliament

iv Regional List MSPs are elected through the Additional Member System, the element of proportional representation that supplements the FPTP system of constituency representatives 


\section{References}

Aldridge, M. (2003) 'The Ties That Divide: Regional Press Campaigns, Community and Populism', Media Culture \& Society 25(4): 491-509.

Berezin, M. (2002) 'Secure States: Toward a Political Sociology of Emotion', in J. Barbalet (ed) Emotions and Sociology, pp. 33-52. Oxford: Blackwell Publishing.

Billig, M. (2008) 'The Language of Critical Discourse Analysis: The Case of Nominalization', Discourse \& Society 19(6): 783-800.

Cross, S. and Lockyer, S. (2006) 'Dynamics of Partisan Journalism', Journalism Studies 7(2): 274.

Fairclough, N. (1995) Media Discourse. London; New York: E. Arnold.

Fairclough, N. (1998) 'Political Discourse in the Media', in A. Bell and P. Garrett (ed) Approaches to Media Discourse, pp. 142-62. Oxford; Malden: Blackwell.

Fairclough, N. (2001) Language and Power. Harlow: Longman.

Fowler, R. (1991) Language in the News: Discourse and ldeology in the Press. London: Routledge.

Habermas, J. (1994) 'Three Normative Models of Democracy', Constellations: An International Journal of Critical \& Democratic Theory 1(1): 1-10.

Hallin, D. C. and Mancini, P. (2004) Comparing Media Systems: Three Models of Media and Politics. Cambridge, U.K.; New York: Cambridge University Press.

Herbst, S. (1998) Reading Public Opinion: How Political Actors View the Democratic Process Chicago, London: University of Chicago Press

Koenig, T. (2004) Routinizing Frame Analysis through the Use of Caqdas, Amsterdam: Loughborough University.

Lewis, J., Inthorn, S. and Wahl-Jorgenson, K. (2005) Citizens or Consumers? What the Media Tell Us About Political Participation. Maidenhead: Open University Press.

McLeod, D. M. and Hertog, J. K. (1992) 'The Manufacture of 'Public Opinion' by Reporters: Informal Cues for Public Perceptions of Protest Groups', Discourse \& Society 3(3): 259-75.

Price, V. (1992) Public Opinion. London: Sage.

Van Dijk, T. A. (1988) News as Discourse. Hillsdale, NJ: L. Erlbaum Associates.

Wahl-Jorgensen, K. (2001) 'Letters to the Editor as a Forum for Public Deliberation: Modes of Publicity and Democratic Debate', Critical Studies in Media Communication 18(3): 303-20. 